\title{
Application of Nuclear Analytical Techniques in Elemental Characterization of Wadi El-Nakhil Alabaster, Central Eastern Desert, Egypt
}

\author{
Zain M. Alamoudi ${ }^{1}$ and A. El-Taher ${ }^{2}$ \\ ${ }^{1}$ Physics Department, Faculty of Science, King Abdulaziz University, Al Faisaliah, Jeddah 21589, Saudi Arabia \\ ${ }^{2}$ Physics Department, College of Science, Al-Azhar University, Assuit 71452, Egypt \\ Correspondence should be addressed to A. El-Taher; atef.eltaher@gmail.com
}

Received 4 April 2016; Revised 13 June 2016; Accepted 20 June 2016

Academic Editor: Arkady Serikov

Copyright (c) 2016 Z. M. Alamoudi and A. El-Taher. This is an open access article distributed under the Creative Commons Attribution License, which permits unrestricted use, distribution, and reproduction in any medium, provided the original work is properly cited.

\begin{abstract}
Instrumental neutron activation analysis (INAA) is a powerful technique for trace element determination in rocks. Nine alabaster samples were collected from Wadi El-Nakhil located at the intersection of lat. $26^{\circ} 10^{\prime} 50^{\prime \prime} \mathrm{N}$ and long. $34^{\circ} 03^{\prime} 40^{\prime \prime} \mathrm{E}$, central Eastern Desert, Egypt, for investigation by INAA and Energy Depressive X-Ray Fluorescence (EDXRF). The samples were irradiated by thermal neutrons at the TRIGA Mainz research reactor at a neutron flux of $7 \times 10^{11} \mathrm{n} / \mathrm{cm}^{2} \cdot \mathrm{s}$. Twenty-two elements were determined, namely, As, Ba, Ca, Co, Cr, Sc, Fe, Hf, K, Mg, Mn, Na, Rb, U, Zn, Zr, Lu, Ce, Sm, La, Yb, and Eu. The chemical analysis of alabaster indicated having high contents of $\mathrm{CaO}$ and $\mathrm{MgO}$ and $\mathrm{LOI}$ and low contents of $\mathrm{SiO}_{2}, \mathrm{Al}_{2} \mathrm{O}_{3}, \mathrm{Na}_{2} \mathrm{O}, \mathrm{K}_{2} \mathrm{O}, \mathrm{MnO}$, and $\mathrm{Fe}_{2} \mathrm{O}_{3}$.
\end{abstract}

\section{Introduction}

Neutron activation analysis (NAA) is based on the irradiation of a sample with neutrons from a neutron source like a nuclear reactor and the subsequent measurement of the induced radioactivity. The NAA has become a very capable multielement analysis technique with improved sensitivity. In many cases, more than 30 elements can be determined from a single experiment [1-3]. The technique is highly sensitive and highly specific. The demand for multielement analysis enhanced the need for the standardization of an absolute method. It is not practiced because of the following reasons. It needs nuclear data set such as atomic mass $(M)$, isotopic abundance, $(\mathrm{n}, \gamma)$ capture cross section $(\sigma)$, absolute $\gamma$-ray abundance, and absolute neutron flux $(\Phi)$. It is well known that measurement of the absolute values of $\Phi$ and $\sigma$ for a reactor neutron spectrum is difficult [4-6].

The Egyptian alabaster is one of the ornamental stones used by ancient Egyptian for art and decorative purposes. The term Egyptian alabaster is applied to a beautifully banded rock composed of crystalline calcium carbonate. It occurs in several locations in the Eastern Desert near the Nile Valley, at Wadi El Assuity, at Wadi Sannur, opposite Beni Suef and Sohag area and near El-Minya El-Gedida, and East Wadi El Shurafa [7]. Given that, there is no specialized database for elemental analysis of alabaster. In the present work, more light will be shed on the elemental content of alabaster. The obtained result can be used as a reference database to those interested in the elemental content of alabaster and those interested in geochemistry and industry of alabaster and other fields.

\section{Geological Setting}

Wadi El-Nakhil alabaster is located at the intersection of lat. $26^{\circ} 10^{\prime} 50^{\prime \prime} \mathrm{N}$ and long. $34^{\circ} 03^{\prime} 40^{\prime \prime} \mathrm{E}$, central Eastern Desert, Egypt. The studied alabaster deposits at Wadi El-Nakhil occur in the form of veins of lensoidal shaped bodies along fault plane trending N59W enclosed in the Eocene limestones. The contacts between alabaster and the enclosing limestones are sharp. The extension of the vein reaches up to $100 \mathrm{~m}$ and its thickness ranges from $30 \mathrm{~cm}$ to $1 \mathrm{~m}$. The alabaster usually displays some xenoliths of limestones up to $30 \mathrm{~cm}$ in diameter. El-Nakhil alabaster is hard, compact body with 
TABLE 1: Irradiation conditions of elements determined [19].

\begin{tabular}{lccc}
\hline Irradiation time & Decay time & Counting time & Elements determined \\
\hline $1 \mathrm{~min}$ & $5 \mathrm{~min}$ & $4 \mathrm{~min}$ & $\mathrm{Mg}$ \\
$5 \mathrm{~min}$ & $1 \mathrm{~h}$ & $15 \mathrm{~min}$ & $\mathrm{~K}, \mathrm{Mn}, \mathrm{Na}$ \\
$6 \mathrm{~h}$ & $2 \mathrm{~d}$ & $1 \mathrm{~h}$ & $\mathrm{U}, \mathrm{Sm}, \mathrm{La}, \mathrm{As}$ \\
$6 \mathrm{~h}$ & $14 \mathrm{~d}$ & $8 \mathrm{~h}$ & $\mathrm{Ba}, \mathrm{Ce}, \mathrm{Co}, \mathrm{Cr}, \mathrm{Sc}, \mathrm{Eu}, \mathrm{Fe}, \mathrm{Hf}, \mathrm{Lu}, \mathrm{Rb}, \mathrm{Yb}, \mathrm{Zn}, \mathrm{Zr}$ \\
\hline
\end{tabular}

banded textures and is characterized by attractive colors and beautiful shapes. The banding is the result of the change in the physicochemical environment of mineralization with time [8]. The banded textures extend laterally and exhibit colloform and botryoidal textures. The thickness of alternating bands varies from 0.2 to $1.2 \mathrm{~cm}$ for the milky white bands and is commonly in the range of 0.3 to $2.8 \mathrm{~cm}$ for the translucent bands. The botryoidal textures usually consist of spherical aggregates ranging from $1 \mathrm{~cm}$ to $12 \mathrm{~cm}$. Some bands are stained reddish brown or black by iron and manganese oxides [9]. Wadi El-Nakhil alabaster deposits occur as hard compact bodies with banded textures. The deposits occur in the form of alternating bands that extend laterally and exhibit colloform and botryoidal textures. Banded texture is common in this alabaster and occurs in the form of successive regular bands in contact with the enclosing limestones. The alabaster has successive milky white and varicolored translucent bands altering with each other. Colloform texture occurs as lining of larger vugs; the colloform banding consists of successive bands with curved surfaces. Botryoidal texture is arranged in the form of spherical aggregates. Quartz grains range in size from fine to medium usually rounded to subangular and nonfractured. Quartz usually occurs as individual grains scattered in the carbonate groundmass. Calcitization of the dolomite crystals predominates during the formation of alabaster. Lee and Harwood [10] stated that this process took place under the effect of meteoric conditions. The replacement of the dolomite by calcite is usually near-surface process and commonly associated with the dissolution of sulfide [11]. Figure 1 shows location map of Wadi El-Nakhil. The full points in the map indicate the sampling sites.

\section{Experimental Technique}

3.1. Samples Preparation and Irradiation. Nine alabaster rock samples were collected from Wadi El-Nakhil located at the intersection of lat. $26^{\circ} 10^{\prime} 50^{\prime \prime} \mathrm{N}$ and long. $34^{\circ} 03^{\prime} 40^{\prime \prime} \mathrm{E}$, central Eastern Desert, Egypt, for investigation by instrumental neutron activation analysis. The samples, each about $1 \mathrm{~kg}$ in weight, were dried in an oven at about $105^{\circ} \mathrm{C}$ to ensure that moisture is completely removed. The powdered samples were sieved using a standard set of sieves to a diameter range of less than $125 \mu \mathrm{m}$ and greater than $63 \mu \mathrm{m}$. Each powdered sample was homogenized using an electric shaker [12-15]. $100 \mathrm{mg}$ from powder alabaster samples was filled in polyethylene capsules and then irradiated with a Dolerite WSE and Microgabbro PMS standard reference material with a flux of $7 \times 10^{11} \mathrm{n} / \mathrm{cm}^{2} \cdot \mathrm{s}$ at the University of Mainz TRIGA research reactor. The concentrations of the elements

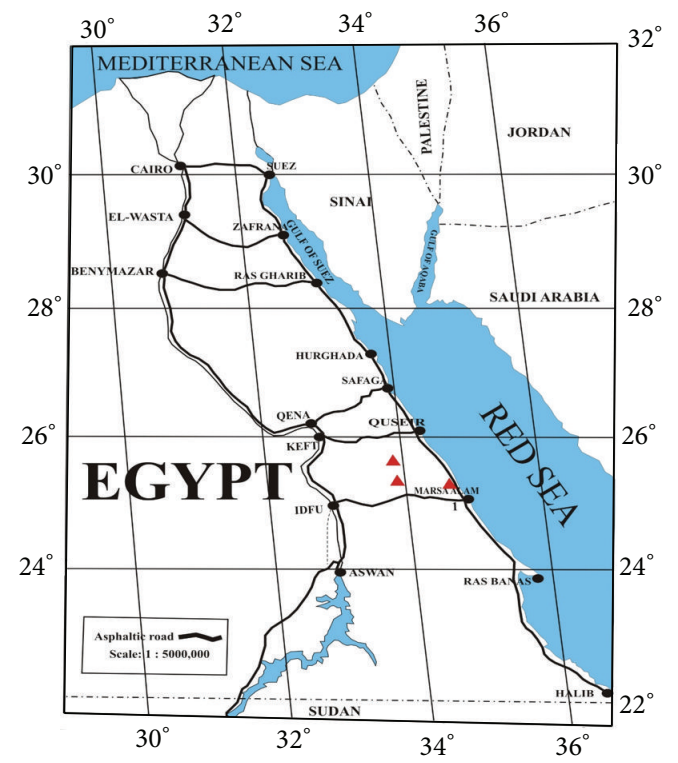

FIGURE 1: Location map of the occurrence of alabaster in the Eastern Desert, Egypt. The full points in the map indicate the sampling sites.

in the irradiated samples were quantitatively determined by comparison with the activities of the reference materials [1618]. After appropriate cooling times, the data were collected for various measurements [19]. Table 1 shows the irradiation conditions for the elements determined.

The measuring of activity concentration for radionuclide in studied samples was defined using gamma-ray spectrometer system by HPGe detector with its electronic circuit. The HPGe detector was equipped with specifications as follows: energy resolution (FWHM) is $1.70 \mathrm{keV}$ at $1.33 \mathrm{MeV}$ Co-60, peak-to-Compton ratio Co-60 is 65.2, and relative efficiency is 29.2 at $1.33 \mathrm{MeV}$ Co-60. The measurements were analyzed and performed by using the Inter-Gamma Software. In all measurements, the electronic dead time is less than $10 \%$ and the Inter-Gamma Software performed the correction automatically $[19,20]$. Table 1 shows the most appropriate irradiation, cooling, and measuring time and the elements determined.

The chemical analyses of major oxide contents in this study were conducted on a Thermo Scientific QUANT'X EDXRF spectrometer, located in the department of physics; all powder samples were dried at a temperature of $105^{\circ} \mathrm{C}$ and stored in desiccators, until they were analyzed. Fill up $3 / 4$ parts of the cup with the sample analyzed. Then, cover the cup with the film. Fix the slim ring by sliding it down and fix the thick ring at the top of the cup. When the cups 
TABLE 2: The nuclear data and the average concentrations of elements determined in alabaster.

\begin{tabular}{|c|c|c|c|c|}
\hline Element & $\begin{array}{c}\text { Activation } \\
\text { product }\end{array}$ & $\begin{array}{c}\text { Energy } \\
\mathrm{keV}\end{array}$ & $T_{1 / 2}$ & Concentrations \\
\hline $\mathrm{Na} \%$ & ${ }^{24} \mathrm{Na}$ & 1369 & $15 \mathrm{~h}$ & 0.20 \\
\hline $\mathrm{Mg} \%$ & ${ }^{27} \mathrm{Mg}$ & 1014 & $9.5 \mathrm{~min}$ & 5.47 \\
\hline $\mathrm{Ca} \%$ & ${ }^{49} \mathrm{Ca}$ & 3984 & $8.7 \mathrm{~min}$ & 45.3 \\
\hline $\mathrm{Mn} \%$ & ${ }^{56} \mathrm{Mn}$ & 846 & $2.6 \mathrm{~h}$ & 0.13 \\
\hline $\mathrm{Fe} \%$ & ${ }^{59} \mathrm{Fe}$ & 1099 & $44.5 \mathrm{~d}$ & 0.93 \\
\hline $\mathrm{K} \%$ & ${ }^{42} \mathrm{~K}$ & 1524.7 & $12.4 \mathrm{~h}$ & 0.86 \\
\hline Sc ppm & ${ }^{46} \mathrm{Sc}$ & 1120 & $38.8 \mathrm{~d}$ & 0.54 \\
\hline Cr ppm & ${ }^{51} \mathrm{Cr}$ & 320 & $27.7 \mathrm{~d}$ & 7.04 \\
\hline Co ppm & ${ }^{60} \mathrm{Co}$ & 1332 & $5.3 y$ & 0.27 \\
\hline Zn ppm & ${ }^{65} \mathrm{Zn}$ & 1115.5 & $244 \mathrm{~d}$ & 7.62 \\
\hline As ppm & ${ }^{76}$ As & 559 & $26.3 \mathrm{~h}$ & 29.05 \\
\hline $\mathrm{Rb}$ ppm & ${ }^{86} \mathrm{Rb}$ & 1076 & $18.6 \mathrm{~d}$ & 0.20 \\
\hline Zr ppm & ${ }^{95} \mathrm{Zr}$ & 756.7 & $64 \mathrm{~d}$ & 28 \\
\hline Ba ppm & ${ }^{131} \mathrm{Ba}$ & 496 & $11.8 \mathrm{~d}$ & 5.08 \\
\hline La ppm & ${ }^{140} \mathrm{La}$ & 1596 & $40.3 \mathrm{~h}$ & 50.37 \\
\hline Ce ppm & ${ }^{141} \mathrm{Ce}$ & 145 & $32.5 \mathrm{~d}$ & 0.43 \\
\hline Eu ppm & ${ }^{152} \mathrm{Eu}$ & 1408 & $13.3 \mathrm{y}$ & 0.04 \\
\hline Sm ppm & ${ }^{153} \mathrm{Sm}$ & 103 & $46.3 \mathrm{~h}$ & 4.17 \\
\hline Yb ppm & ${ }^{169} \mathrm{Yb}$ & 198 & $32 \mathrm{~d}$ & 0.15 \\
\hline Lu ppm & ${ }^{177} \mathrm{Lu}$ & 208.4 & $161 \mathrm{~d}$ & 0.17 \\
\hline Hf ppm & ${ }^{181} \mathrm{Hf}$ & 428 & $42.4 \mathrm{~d}$ & 0.37 \\
\hline U ppm & ${ }^{239} \mathrm{~Np}$ & 106 & $2.4 \mathrm{~d}$ & 2.3 \\
\hline
\end{tabular}

are prepared, place them on the sample stage inside the spectrometer chamber, with the side to be analyzed facing down toward the X-ray tube (QUANT'X Technical Manual, Thermo Fisher Scientific, 2008).

\section{Results and Discussion}

Table 2 shows the average concentration values of nine alabaster samples in four irradiation cycles. Twenty-two elements were identified. The elements determined are $\mathrm{Na}$, $\mathrm{Mg}, \mathrm{Ca}, \mathrm{Mn}, \mathrm{Fe}, \mathrm{K}, \mathrm{Sc}, \mathrm{Cr}, \mathrm{Co}, \mathrm{Zn}, \mathrm{As}, \mathrm{Rb}, \mathrm{Zr}, \mathrm{Ba}, \mathrm{La}, \mathrm{Ce}, \mathrm{Eu}$, $\mathrm{Sm}, \mathrm{Yb}, \mathrm{Lu}, \mathrm{Hf}$, and $\mathrm{U}$. The concentration for all elements was expressed in ppm except for $\mathrm{Na}, \mathrm{Mg}, \mathrm{Ca}, \mathrm{Mn}, \mathrm{Fe}$, and $\mathrm{K}$ which were given in \%. The concentration of determined elements was specified by means of multiple activities produced by $(\mathrm{n}, \gamma)$ reactions, since some of the radionuclides determined exhibit more than one obvious and distinct gamma line. In all other situations, the elements were measured by their most distinctive peaks, with lowest statistical error, free of interference. The measurements accuracy has been estimated using the PMS and WSE analysis, for the standard reference materials. From the obtained results, we can say that INAA is an effective and successful method to supply valuable data for clay samples with a satisfying precision. The accuracy for most elements in present results is in the range of $10 \%$ of the reference values, and a good precision has been shown in most results [21].
The statistical counting errors were

$$
\begin{aligned}
& <2 \% \text { for } \mathrm{Na}, \mathrm{Mn}, \mathrm{Sc}, \mathrm{Co}, \mathrm{Hf} \text {, and } \mathrm{Sm}, \\
& 2-5 \% \text { for } \mathrm{Eu}, \mathrm{La}, \mathrm{Cr}, \mathrm{Fe}, \mathrm{Ce}, \mathrm{Yb} \text {, and } \mathrm{Lu} \text {, } \\
& 5-10 \% \text { for } \mathrm{Zn}, \mathrm{As}, \mathrm{K}, \mathrm{Mg} \text {, and } \mathrm{Ca}, \\
& 10-15 \% \text { for } \mathrm{Rb}, \mathrm{Ba} \text {, and } \mathrm{U} \text {. }
\end{aligned}
$$

Quantitative analysis was carried out for each isotope by comparing the activities from the most favorable peaks in the gamma spectra of samples with those of the standard reference material. In this analysis the highest-energy peaks were usually used, as in the case of ${ }^{59} \mathrm{Fe},{ }^{140} \mathrm{La}$, and ${ }^{46} \mathrm{Sc}$, since these peaks normally had less interference than lowerenergy peaks due to the Compton effect. In some cases, the use of low-energy gamma lines permitted the determination of some elements, since these radionuclides have no highenergy peak, as in the case of ${ }^{141} \mathrm{Ce}$ and ${ }^{153} \mathrm{Sm}$. Scandium is the most favorable element to be determined by INAA, due to the $100 \%$ abundance of its single stable nuclide and its $100 \%$ branching ratio of the measured gamma lines at $889.4 \mathrm{keV}$ and $1120.5 \mathrm{keV}$ and its convenient half-life of 83.8 days [22].

The rare earth elements determined are $\mathrm{La}, \mathrm{Ce}, \mathrm{Sm}, \mathrm{Eu}$, $\mathrm{Yb}$, and $\mathrm{Lu}$. The selection of photopeaks for the analysis is briefly discussed below for each element. For lanthanum, the high abundance photopeak of ${ }^{140} \mathrm{La}$ at $1596 \mathrm{keV}$ was used, which is free of interference. The other peak at $487 \mathrm{keV}$ cannot be used due to interferences from ${ }^{47} \mathrm{Ca} 489 \mathrm{keV}$ and ${ }^{192} \mathrm{Ir} 488 \mathrm{keV}$. For cerium, the photopeak of ${ }^{141} \mathrm{Ce}$ at $145 \mathrm{keV}$ was used. For samarium, the isotope ${ }^{153} \mathrm{Sm}$ is used. As far as europium is concerned, ${ }^{152} \mathrm{Eu}$ has a number of photopeaks where the high abundance peaks at 1408 and $799 \mathrm{keV}$ are free from interference. Both peaks were used for the determination of this element. Another peak at $122 \mathrm{keV}$ cannot be resolved from the $124 \mathrm{keV}$ line of ${ }^{154} \mathrm{Eu}$. However, the combined peaks can be used as these are obtained from two isotopes of the same element and have similar half-lives. Ytterbium can be determined using the $198 \mathrm{keV}$ peak of ${ }^{169} \mathrm{Yb}$. The $396 \mathrm{keV}$ peak cannot be resolved from nearby peaks of ${ }^{152} \mathrm{Eu} 383 \mathrm{keV}$ and ${ }^{233} \mathrm{~Pa} 381 \mathrm{keV}$. For lutetium, the high abundance peak at $208 \mathrm{keV}$ of ${ }^{177 \mathrm{~m}} \mathrm{Lu}$ was used [23-25].

The concentration of uranium via ${ }^{238} \mathrm{U}$ in alabaster samples was measured according to the following equation:

$$
{ }^{238} \mathrm{U}(\mathrm{n}, \gamma){ }^{239} \mathrm{U} \stackrel{\beta^{-}}{\longrightarrow}{ }^{239} \mathrm{~Np} \quad E \gamma=106 \mathrm{keV} .
$$

The feature $\gamma$-rays can be detected using $\gamma$-spectroscopy [23].

The isotopes ${ }^{140} \mathrm{La},{ }^{141} \mathrm{Ce}$, and ${ }^{147} \mathrm{Nd}$ commonly used in the activation analysis of the corresponding elements are also produced by fission of ${ }^{235} \mathrm{U}$. There is a possibility of interference of the $320 \mathrm{keV}^{51} \mathrm{Cr}$ line with the $319.4 \mathrm{keV}^{147} \mathrm{Nd}$ line, but neodymium has not been identified in any of the $\gamma$ ray spectra. Scandium was determined from the $889 \mathrm{keV}$ line intensity, which is not interfered with by any of the activation products [24-26]. Table 3 shows interferences due to energy and reactions.

The results of chemical analysis of alabaster samples are given in Table 4. In the studied alabaster, $\mathrm{CaO}$ ranges from 
TABLE 3: Interferences due to energy and reactions.

\begin{tabular}{lccr}
\hline Radionuclide & $E \gamma, \mathrm{keV}$ & \multicolumn{2}{c}{ Reaction interferences } \\
& & Interfering contribution $\mu \mathrm{g} / \mu \mathrm{g}$ \\
\hline${ }^{140} \mathrm{La}$ & 1596.2 & $\mathrm{U}(\mathrm{n}, \gamma){ }^{140} \mathrm{La}$ & 0.032 \\
${ }^{141} \mathrm{Ce}$ & 145.5 & $\mathrm{U}(\mathrm{n}, \gamma){ }^{141} \mathrm{Ce}$ & 0.201 \\
${ }^{147} \mathrm{Nd}$ & 91.1 & $\mathrm{U}(\mathrm{n}, \gamma){ }^{147} \mathrm{Nd}$ & 0.187 \\
\hline
\end{tabular}

TABLE 4: Chemical analysis of major oxide contents (wt\%) of Wadi El-Nakhil alabaster.

\begin{tabular}{lcccccccccc}
\hline Oxides & 1 & 2 & 3 & 4 & 5 & 6 & 7 & 8 & 9 & Average \\
\hline $\mathrm{CaO}$ & 62.2 & 50.45 & 66.32 & 64.36 & 69.68 & 69.6 & 70.75 & 64.4 & 66.3 & 64.9 \\
$\mathrm{MgO}$ & 12.22 & 21.56 & 7.23 & 8.9 & 3.23 & 1.21 & 4.03 & 8.8 & 7.3 & 8.28 \\
$\mathrm{SiO}_{2}$ & 1.2 & 0.06 & 0.05 & 0.04 & 0.04 & 1.61 & 0.95 & 1.42 & 1.8 & 0.79 \\
$\mathrm{Fe}_{2} \mathrm{O}_{3}$ & 1.08 & 1.35 & 1.08 & 1.08 & 1.24 & 1.58 & 1.10 & 1.07 & 1.08 & 1.18 \\
$\mathrm{Na}_{2} \mathrm{O}$ & 0.18 & 0.27 & 0.22 & 0.54 & 0.21 & 0.18 & 0.19 & 0.53 & 0.23 & 0.28 \\
$\mathrm{~K}_{2} \mathrm{O}$ & 1.03 & 1.09 & 1.04 & 1.02 & 1.03 & 1.03 & 1.02 & 1.02 & 1.03 & 1.03 \\
$\mathrm{P}_{2} \mathrm{O}_{5}$ & 0.01 & 0.1 & 0.01 & 0.04 & 0.01 & 0.07 & 0.01 & 0.04 & 0.01 & 0.03 \\
$\mathrm{LOI}$ & 24.9 & 24.6 & 25.6 & 25.1 & 25.8 & 25.15 & 24.8 & 25.2 & 25.5 & 25.2 \\
\hline
\end{tabular}

50.45 to $70.75 \%$ with an average of $64.9 \%$. MgO ranges from 1.21 to $21.5 \%$ with an average of $8.28 \%$. $\mathrm{SiO}_{2}$ content ranges from 0.4 to $1.8 \%$ with an average of $0.79 \%$. Small quartz grains in the silicified carbonate bands in some alabaster samples represent silica. $\mathrm{Fe}_{2} \mathrm{O}_{3}$ ranges from 1.07 to $1.58 \%$ with an average of $1.18 \% . \mathrm{Na}_{2} \mathrm{O}$ contents range from 0.18 to $0.54 \%$ with an average of $0.28 \% . \mathrm{P}_{2} \mathrm{O}_{5}$ ranges from 0.01 to $0.1 \%$ with an average of $0.03 \%$. LOI $\left(\mathrm{H}_{2} \mathrm{O}^{+}\right)$ranges from 24.6 to $25.5 \%$ with an average of $25.2 \%$.

\section{Conclusion}

Twenty-one elements were determined including major and trace elements in addition to some rare earth elements. The chemical analyses of alabaster reveal the enrichment of $\mathrm{CaO}$ and $\mathrm{MgO}$ and LOI and the depletion of $\mathrm{SiO}_{2}, \mathrm{Al}_{2} \mathrm{O}_{3}, \mathrm{Na}_{2} \mathrm{O}$, $\mathrm{K}_{2} \mathrm{O}, \mathrm{MnO}$, and $\mathrm{Fe}_{2} \mathrm{O}_{3}$. The source of calcium is dissolution of Eocene limestone due to the action of meteoric water.

\section{Competing Interests}

The authors declare that they have no competing interests.

\section{Acknowledgments}

This work was funded by the Deanship of Scientific Research (DSR), King Abdulaziz University, Jeddah, under Grant no. 363-651-D1435. The authors, therefore, acknowledge with thanks DSR technical and financial support.

\section{References}

[1] D. Schlösser, D. Baacke, P. Beuge, and K.-L. Kratz, "Elemental composition of sediments from a former silver mine in Freiberg/East Germany," Applied Radiation and Isotopes, vol. 50, no. 3, pp. 609-614, 1999.
[2] N. F. Soliman, N. Walley El-Dine, L. S. Ashmawy, A. Sroor, and T. El Sayed Mohamed, "Investigation of six geological samples from Wadi Sitra Eastern Desert, Egypt Using $\mathrm{K}_{0}$ neutron activation method," The International Journal of Applied Radiation and Isotopes, vol. 5, pp. 59-71, 2009.

[3] S. M. El-Bahi, A. Sroor, and A. S. Abdel-Haleem, "Application of neutron activation analysis technique for gold estimation in mines in southern Egypt," Applied Radiation and Isotopes, vol. 50, no. 3, pp. 627-630, 1999.

[4] M. E. Montero Cabrera, H. Herrera Hernández, E. Herrera Peraza, N. Rodríguez Martínez, and M. C. López Reyes, "Instrumental neutron activation analysis of rocks from Cayajabos petroleum ore," Applied Radiation and Isotopes, vol. 52, no. 1, pp. 143-146, 2000.

[5] A. Sroor, N. Abdel-Basset, A. S. Abdel-Haleem, and A. M. Hassan, "Elemental analysis of two Egyptian iron ores and produced industrial iron samples by neutron activation analysis," Applied Radiation and Isotopes, vol. 54, no. 3, pp. 559-562, 2001.

[6] L. C. Dinescu and O. G. Duliu, "Heavy metal pollution of some Danube Delta lacustrine sediments studied by neutron activation analysis," Applied Radiation and Isotopes, vol. 54, no. 5, pp. 853-859, 2001.

[7] M. K. Akaad and M. H. El Naggar, "Petrography of the Egyptian alabaster of wadi Sannur," Bulletin, Faculty of Science, Alexandria University, vol. 6, pp. 157-167, 1964.

[8] J. R. Craig and D. J. Vaughan, Ore Microscopy and Ore Petrography, A Wiley Interscience Publication, New York, NY, USA, 1981.

[9] I. A. Salem, B. T. El Dosuky, G. A. Aly, and A. N. Ahmed, "Contribution of the mineralogical and geochemical characteristics of the Egyptian alabaster from Wadi El Nakhil, Central eastern desert," in Proceedings of the 8th International Conference on Geochemistry, vol. 2, pp. 1-23, Alexandria University, August 2008.

[10] M. R. Lee and G. M. Harwood, "Dolomite calcitization and cement zonation related to uplift of the Raisby Formation (Zechstein carbonate), Northeast England," Sedimentary Geology, vol. 65, no. 3-4, pp. 285-305, 1989. 
[11] M. E. Tucker, Sedimentary Petrology, vol. 260, Blackwell Scientific Publications, Oxford, UK, 1991.

[12] A. El-Taher, "Rare-earth elements in Egyptian granite by instrumental neutron activation analysis," Applied Radiation and Isotopes, vol. 65, no. 4, pp. 458-464, 2007.

[13] A. El-Taher and M. A. K. Abdelhalim, "Elemental analysis of limestone by instrumental neutron activation analysis," Journal of Radioanalytical and Nuclear Chemistry, vol. 299, no. 3, pp. 1949-1953, 2014.

[14] A. El-Taher and M. A. K. Abdelhalim, "Elemental analysis of soils from Toshki by using instrumental neutron activation analysis techniques," Journal of Radioanalytical and Nuclear Chemistry, vol. 300, no. 1, pp. 431-435, 2014.

[15] A. El-Taher, K.-L. Kratz, A. Nossair, and A. H. Azzam, "Determination of gold in two Egyptian gold ores using instrumental neutron activation analysis," Radiation Physics and Chemistry, vol. 68, no. 5, pp. 751-755, 2003.

[16] A. El-Taher, A. Nossair, A. M. Azzam, K.-L. Kratz, and A. S. Abdel-Halim, "Determination of traces of uranium and thorium in some Egyptian environmental matrices by instrumental neutron activation analysis," Environment Protection Engineering, vol. 30, no. 1-2, pp. 19-30, 2004.

[17] H. M. Mahmoud, A. G. E. Abbady, M. A. Khairy, A. S. Abdehalim, and A. El-Taher, "Multi-element determination in sandstone rock by instrumental neutron activation analysis," Journal of Radioanalytical and Nuclear Chemistry, vol. 264, no. 3, pp. 715-718, 2005.

[18] A. El-Taher and M. A. M. Uosif, "The assessment of the radiation hazard indices due to uranium and thorium in some Egyptian environmental matrices," Journal of Physics D: Applied Physics, vol. 39, no. 20, pp. 4516-4521, 2006.

[19] Kernchemie Report Tables for Neutron Activation Analysis, Triga Mainz Research Reactor, Nuclear Chemistry Institute, Mainz, Germany, 1989.

[20] A. El-Taher, "Elemental analysis of two Egyptian phosphate rock mines by instrumental neutron activation analysis and atomic absorption spectrometry," Applied Radiation and Isotopes, vol. 68, no. 3, pp. 511-515, 2010.

[21] A. Alharbi and A. El-Taher, "Elemental analysis of quartz by instrumental neutron activation analysis," Applied Radiation and Isotopes, vol. 82, pp. 67-71, 2013.

[22] A. El-Taher, "Determination of chromium and trace elements in El-Rubshi chromite from Eastern Desert, Egypt by neutron activation analysis," Applied Radiation and Isotopes, vol. 68, no. 9, pp. 1864-1868, 2010.

[23] L. Zhao, F.-S. Zhang, and J. Zhang, "Chemical properties of rare earth elements in typical medical waste incinerator ashes in China," Journal of Hazardous Materials, vol. 158, no. 2-3, pp. 465-470, 2008.

[24] Y. Suzuki, T. Suzuki, and N. Furuta, "Determination of Rare Earth Elements (REEs) in Airborne Particulate Matter (APM) collected in Tokyo, Japan, and a positive anomaly of Europium and Terbium," Analytical Sciences, vol. 26, no. 9, pp. 929-935, 2010.

[25] A. El-Taher, "Rare earth elements content in geological samples from eastern desert, Egypt, determined by instrumental neutron activation analysis," Applied Radiation and Isotopes, vol. 68, no. 9, pp. 1859-1863, 2010.

[26] A. El-Taher, "INAA and DNAA for uranium determination in geological samples from Egypt," Applied Radiation and Isotopes, vol. 68, no. 6, pp. 1189-1192, 2010. 

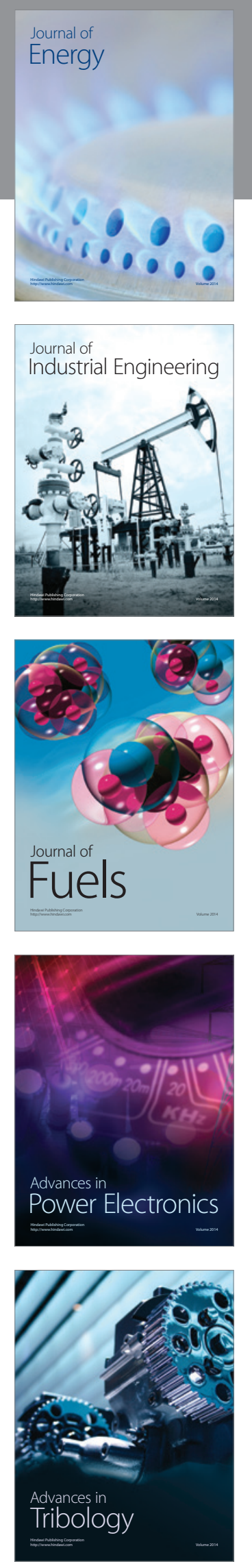
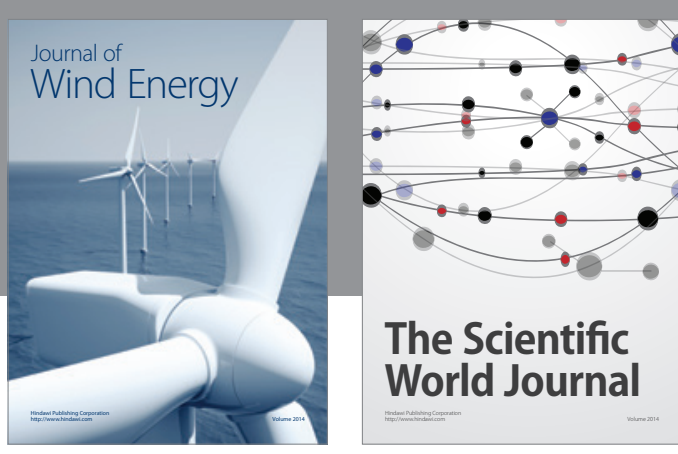

The Scientific World Journal
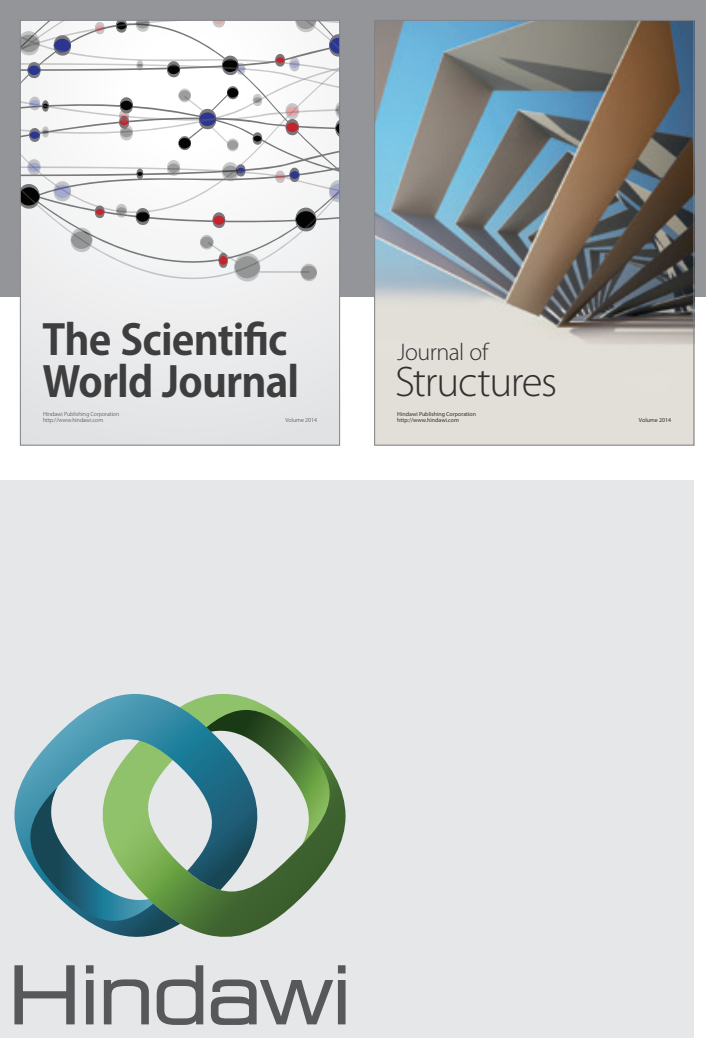

Submit your manuscripts at

http://www.hindawi.com
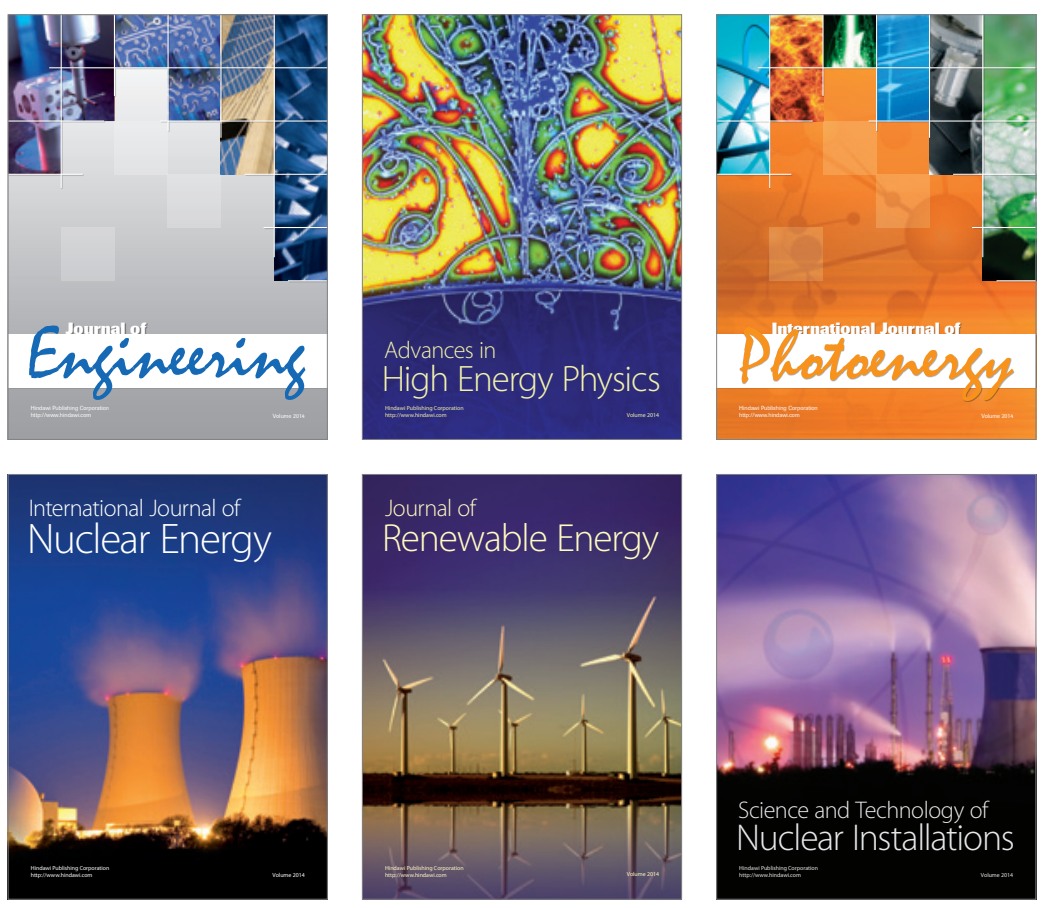
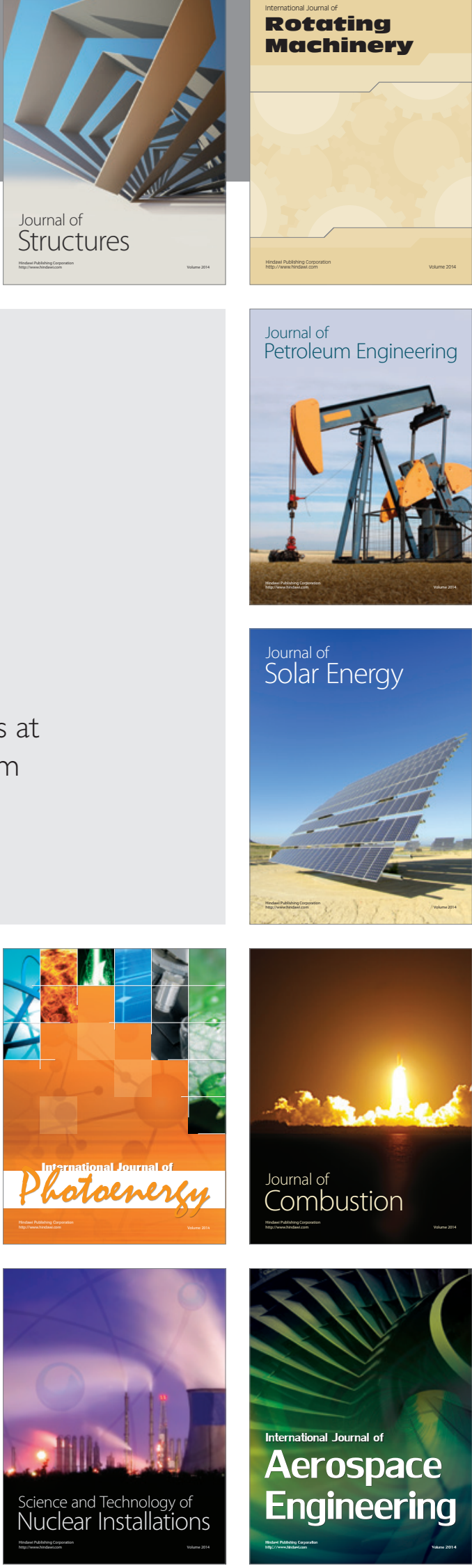